The working party surveyed the present position in the United Kingdom and at the same time compared it with the contribution which such establishment staff make to formal teaching in The Netherlands. It was impressed by the educational effort already made within the present mandates, and it concludes in its report, entitled The Educational Role of the Ministry of Aviation Establishments*, that, as regards general scientific education, some encouragement and the removal of certain obstacles are all that are required.

On the other hand, as regards training which leads to design and development, the position is less satisfactory and it is here that the main responsibility of the establishments lios. The working party recommends that any establishment concerned with research and development in a given branch of technology should be encouraged to accept certain responsibilities for advanced training in this field and for seeing that educational potential resulting from its own work is properly utilized. This teaching mandate should be exercised not only as already in sandwich courses but also in postgraduate training in

* Ministry of Aviation: Electronics Research Council. The Educational Role of the Ministry of Aviation Establishments-Working Party Report. Pp. iv +24. (London: H.M.S.O., 1966.) 2s. 3d. net.

\section{EXOTIC ACACIAS IN SOUTH AFRICA}

A NUMBER of Australian phyllode-bearing acacias introduced into the Cape Peninsula of South Africa are now conspicuous members of the local vegetation. They include Acacia melanoxylon, A. longifolia, A. cyclops and $A$. cyanophylla. At first cultivated, they have for some decades been spreading by natural means, and the tendency of the different specios to occupy particular habitats is evident. On the assumption that the salt content of soil could influence distribution, a greenhouse investigation has been made by Prof. E. A. Roux of the tolerance of these plants to sodium chloride ${ }^{1}$.

Young plants were grown in water culture in washed river sand. A full nutrient solution of low osmotic pressure $(0.5$ atmospheres) was used as the basic medium, to which was added pure sodium chloride in varying amounts. Aeration was achieved by draining the containers daily. After the seedlings were established in the basic medium, they were subjected to increasing concentrations of sodium chloride until they died. The limits of tolorance were found to rise if the increases in salt concentration were made at longer as opposed to shorter intervals. Plants subjected directly to certain high concentrations were killed immediately.

With slow increases of concentration, A. melanoxylon would tolerate up to $2 \cdot 4$ per cent sodium chloride, $A$. longifolia up to $3 \cdot 6$ per cent and $A$. cyclops and $A$. cyanophylla up to 4.0 per cent. Other experiments indicated A. cyanophylla. grows up to the $1,000-\mathrm{ft}$. contour.

${ }^{1}$ South African J. of Sei., 61, No. 12 (1965). technology, and occasional teaching in postgraduate courses at the universities. To this end, the working party recommends that universities should be encouraged to offer selected members of establishment staffs parttime teaching positions with responsibilities particularly for postgraduate teaching similar to those in Holland.

The working party also believes that university and technical college staff should be encouraged to use research facilities in establishments and given in establishment programmes. Furthermore, it considers that the Ministry of Aviation should discuss with the Science Research Council ways to take account of this possibility in allocating research grants-provided that use of the facilities is more or less guaranteed. It also suggests that establishments should continue to place research contracts in universities, especially for work likely to lead to military or commercial development.

Finally, it recommends that special relations between the establishments and neighbouring universities should be developed where appropriate and that location of neighbouring research establishments should be taken into account when starting new universities or colleges, and vice versa.

that $A$. cyclops was slightly less tolerant to salt than

As a result of all the experiments, the species were finally placed in the following order of increasing salt tolerance: A. melanoxylon, $A$. longifolia, $A$. cyclops, $A$. cyanophylla. This sequence bears a direct relation to the altitudes at which the species normally grow on the Table Mountain range. A. melanoxylon grows above the $2,000-\mathrm{ft}$. contour. The upper limit indicated for $A$. cyclops is about $1,000 \mathrm{ft}$. and, for $A$. cyanophylla, slightly less. A. longifolia

Prof. Roux plans soil tests so as to determine the average salt content of the soils in the different regions, but general physiographic considerations would point to an increase in salinity with decreasing altitude. The two spocies most highly tolerant of sodium chloride, A. cyclops and $A$. cyanophylla, are dominant on the Cape Flats where altitudes are generally less than $100 \mathrm{ft}$. above sea level. A. cyclops is the dominant and often the only species on dunes near the sea, and it was interesting to discover that it is rather less tolerant of salt than $A$. cyanophylla which tends to dominate on the more consolidated and level areas. It seems probable that drainage is more officient on the dunes and that the consolidated and less-well-drained soils have a higher salt, content.

T. H. HAwKINS

\title{
AN INVESTIGATION OF MICROPULSATIONS AT MIDDLE LATITUDES
}

\author{
By M. J. USHER and W. F. STUART* \\ Department of Geophysics, Imperial College of Science and Technology, University of London
}

$\mathrm{R}^{\mathrm{v}}$ UBIDIUM magnetometers were set up at the three United Kingdom observatories (Lerwick, geomagnetic latitude $62 \cdot 5^{\circ} \mathrm{N}$., Eskdalemuir $58 \cdot 4^{\circ} \mathrm{N}$., Hartland $54.6^{\circ} \mathrm{N}$.) and simultaneous recordings of micropulsations occurring in the total field were obtained for the second half of 1964. The three stations are close to the same geomagnetic longitude and are about equally spaced at intervals of 400 miles.

* Present address: Department of Meteorology, University of Edinburgh.
The rubidium magnetometer is an atomic oscillator producing a frequency proportional to the scalar value of the ambient nagnetic field. Details of its method of operation have been givon earlier ${ }^{1,2}$. T'ho magnetometer frequency of about $200 \mathrm{kc} / \mathrm{s}$ in the total Earth's field was counted by a commercial 1-Me/s unit and decoded into an analogue step record. The sensitivity was $1 / 20 \gamma$ with a sampling rate of about 1 per sec, which ensured that the frequency response of the system was flat from very long periods to 5 sec: a chart speed of $0.25 \mathrm{in}$. per 